\title{
Isı Değiştiricideki Yüzey Deseninin Isı Transferine Etkisinin İncelenmesi
}

\author{
Ersin HAYDARASLAN ${ }^{*}$, Ramazan SELVER ${ }^{2}$
}

${ }^{1}$ Recep Tayyip Erdoğan Üniversitesi, Elektrik ve Enerji Bölümü, 53100, Rize

2Süleyman Demirel Üniversitesi, Mühendislik Fakültesi, Makine Mühendisliği Bölümü, 32260, Isparta

(Alınış / Received: 20.12.2017, Kabul / Accepted: 24.07.2018, Online Yayınlanma / Published Online: 16.08.2018)

\section{Anahtar Kelimeler}

Dikdörtgen prizma șekli ısı değiștirici, Diyagonal desenli ısı değiştirici,

Isı transferi,

Nümerik analiz,

Fluent programı
Özet: Bu çalışmada, bir ısı değiştirici üzerindeki desenin ısı transferine etkisi sayısal modelleme metoduyla incelenmiștir. Dikdörtgenler prizması şeklinde iki ısı değiştirici Ansys Fluent R17.2 programı ile modellenmiş ve simüle edilmiștir. Birinci ısı değiștiricinin bütün yüzeyleri düz, ikincinin ise sadece alt ve üst yüzeyleri diyagonal desenli tasarlanmıștır. Diyagonal desenin akışkanın çıkış sıcaklığına, ısı transfer miktarına, akış hızına, akış alanına ve basınç değişimine etkisi incelenmiştir. Her iki model için farklı kütlesel debilerde nümerik çözümler yapılmıștır. Çalıșmanın sonunda, akışkanların çıkış sıcaklıkları kıyaslandığında; desenli ısı değiştiricinin çıkış sıcaklığı incelenen bütün debiler için daha düşük çıkmıştır. Her iki modeldeki ISI transferi incelendiğinde; desenli ISı değiştiricideki ISI transferinin düz olana göre daha fazla olduğu görülmüștür. Isı değiștiricilerdeki akışkan hızları kıyaslandığında; desenli ısı değiştiricideki akış hızının, iç çeperlerindeki desenlerden kaynaklanan periyodik ve bölgesel kesit daralmalarından dolayı desenli bölgelerde arttı̆̆ görülmüștür. Ayrıca desenlerin basınç değişimine etkisi incelendiğinde; desenli ısı değiștiricideki diyagonal desenlerden dolayı düz olana göre daha fazla basınç kaybı olduğu belirlenmiștir.

\section{Investigation of the Effect of Surface Pattern of a Heat Exchanger on Heat Transfer}

\section{Keywords}

Rectangular prism shaped heat exchanger,

Heat exchanger with diagonal pattern, Heat transfer,

Numerical analysis,

Fluent program

\begin{abstract}
In this study, the effect of the pattern on a heat exchanger on heat transfer was examined by using numerical modeling method. Two heat exchangers in the form of rectangular prisms were modeled and simulated by using the Ansys Fluent R17.2 program. All the surfaces of the first heat exchanger were flat and only the upper and lower surfaces of the second one were designed diagonally pattern. The effect of the diagonal pattern on the outlet temperature of the fluid, the amount of heat transfer, the flow rate, the flow field and the pressure variation were investigated. For both models, numerical solutions were made on different mass flow rate. As a result, when the outlet temperatures of the fluids were compared, the outlet temperature of the patterned heat exchanger was lower for all the mass flow rates examined. When examining the heat transfer in both models; it was seen that the heat transfer in the patterned heat exchanger was higher than in the flat one. When fluid velocities in heat exchangers were compared; it was seen that the flow velocities in the patterned heat exchanger increased in the patterned regions due to the periodic and regional cross-sectional narrowing caused by the patterns on the inner walls. In addition, when the effect of the patterns on the pressure variation was examined; the patterned heat exchanger was determined to have more pressure loss than the flat one due to diagonal patterns.
\end{abstract}

\section{Giriş̧}

Isı değiştiriciler endüstride farklı boyutlarda ve farklı tasarım parametreleriyle üretilmektedir. Ancak hacim, ağırlık, ısıl performans, maliyet gibi parametrelerin iyileştirilmesi üzerine birçok çalışma yapılmaktadır. Bu çalışmalardan; Pethkool vd. [1] eş eksenli helisel oluklu ısı değiștirici tüpünde, adımın 
ve diş yüksekliğinin çapa oranının ısı transferi, sürtünme ve isısal faktörler üzerindeki etkisini deneysel incelemişlerdir. Deney sonuçlarında, düz tüpe kıyasla helisel oluklu tüpün ısı transferinin ve sıcak akışkandan soğuk akışkana doğru gerçekleşen ıSı transfer miktarının önemli ölçüde arttığını görmüşlerdir. Wang vd. [2] yeni elipsoit çukurlu bir ISı transfer borusu geliştirip, isı transferi ve hidrodinamik analiz bakımından deneysel incelemişlerdir. Kendi tasarladıkları çukurlu isı transfer boruları ile düz isı transfer borularını kıyasladıklarında; ısı transferinin \%87'ye kadar arttığını belirlemişlerdir. Garcia vd. [3] oluklu tüp, çukurlu tüp ve bobin şeklinde sarılmış telli tüp olmak üzere üç değişik geliştirme tekniğinde yapay pürüzlülüğe sahip ısı değiştiricilerin ısısal-hidrolik davranışlarını deneysel incelemişlerdir. Reynolds sayısı 200'den düşük olan akışlar için düz tüplerin kullanımını tavsiye etmişlerdir. Reynolds sayısı 200 ile 2000 arasında bobin şeklinde sarılmış telli tüplerin kullanımını, 2000'den yüksek akışlar için oluklu veya çukurlu tüplerin kullanımını, aynı ısı transfer katsayıları için daha az basınç düşüşünden dolayı avantajlı bulmuşlardır. Carija vd. [4] çok sıralı kanatçıklı ve borulu ısı değiştiricide, akışkan hareketlerini ve ısı değişimini deneysel ve nümerik incelemişlerdir. Kanatçıklı ısı değiştiricileri üzerinde yapılan hesaplamaların, düz ısı değiştiriciye göre ısı transfer karakteristiği bakımından önemli ölçüde daha iyi olduğunu ancak basınç düşüșünün fazla olduğunu görmüşlerdir. Dizaji vd. [5] oluklu iç ve dış tüpten oluşan çift borulu isı değiştirgecideki ISı transferini, basınç düşüşünü ve ısısal etkinliği deneysel incelenmişlerdir. Diş boruda içe doğru, iç boruda dışa doğru oluşturulan oluğun isı transferi miktarını önemli ölçüde artırdığını görmüşlerdir. Yogesh vd. [6] çeşitli eliptik oranlarda ve yönlerde borulara sahip ısı değiștiricinin sürtünme ve ısı transfer karakteristiğini nümerik olarak incelemişlerdir. Çalışmanın sonucunda eliptiklik oranı 0.6, eğim açısı $20^{\circ}$ olan kanatlı borulu ısı değiştiricinin ısı transferi açısından en iyi performansa sahip olduğunu görmüşlerdir. Zheng vd. [7] borulu ısı değiştirici üzerinde bulunan vorteks üretici parçaların ısı transferine etkisini nümerik incelemişlerdir. Eklenen parçaların çapının ve yerleşim açısının ısı transferini ve sürtünme karakteristiğini önemli derecede etkilediğini görmüşlerdir. Samadifar vd. [8] farklı vorteks üreticilerin kanatçıklı ısı değiştiricideki kanal sıcaklığı ve ısı transfer katsayısına etkisini nümerik incelemişlerdir. Çalışmada altı farklı vorteks üretici kullanılmış ve bunların ısı transferini \%7'ye kadar artırdığını ancak basınç düşüşünü olumsuz etkilediklerini görmüşlerdir.

$\mathrm{Bu}$ çalışmada ise, dikdörtgenler prizması şeklinde iki ısı değiştirici Ansys Fluent R17.2 programı ile modellenip simüle edilmiştir. Birinci ısı değiştiricide bütün yüzeyler düz (desensiz), ikincide ise sadece alt ve üst yüzeyleri diyagonal desenli tasarlanmıştır. Isı değiştiricinin yüzeyine eklenen diyagonal desenin akışkanın çıkış sıcaklığına, ısı transfer miktarına, akış hızına, akış alanına ve basınç değişimine etkisi değerlendirilmiștir. Her iki ısı değiștirici için altı farklı kütlesel debide nümerik çözümler yapılmıştır. Endüstride bu tip ısı değiştiriciler plakalı soğutucu olarak kullanılmaktadır.

\section{Metot}

Çalışmada dikdörtgenler prizması şeklinde, bir tanesi $1000 \times 200 \times 40 \mathrm{~mm}$, diğeri 1077,9 × 200 × $40 \mathrm{~mm}$ boyutlarında iki ısı değiștirici modellenip simüle edilmiştir. Modelleme ve simülasyon için Ansys Fluent R17.2 programı kullanılmıștır [9]. Farklı Reynolds sayılarında çelik malzemelerden meydana gelen ısı değiştiricileri ile nümerik çözümler yapılmıştır. Bu çözümlerde program içerisinde var olan denklemler; akışkanlar ve isı transferinde kullanılan Süreklilik denklemi, Navier-Stokes (N-S) denklemleri ve Enerji denklemleri birlikte kullanılmıştır.

Isı değiştiricinin yatay konumu için giriş ve çıkış noktalarındaki potansiyel enerji farkı yoktur. Z yönündeki hız ise simetriden dolayı sabit ve sıfırdır. Süreklilik denklemi kartezyen koordinatlarda zamandan bağımsız nümerik çözdürüldüğünden dolayı, kütlenin korunumu için diferansiyel denklem;

$$
\frac{\partial(\rho u)}{\partial x}+\frac{\partial(\rho v)}{\partial y}=0
$$

şeklinde ifade edilmiştir [10]. N-S Denklemleri kartezyen koordinatlarda konum ve vektör bileşenleri $(\mathrm{x}, \mathrm{y})$ ve hız bileşenleri $(\mathrm{u}, \mathrm{v})$ cinsinden açlabilir. Buna göre sıkıștırılamaz (hava sıkıştırabilir olmasına rağmen konfigürasyonda yoğunluğunun değişmediğini kabul ederek) N-S denklemlerinin $(x, y)$ bileşenleri sırası ile;

$$
\begin{aligned}
& \rho\left(u \frac{\partial u}{\partial x}+v \frac{\partial u}{\partial y}\right)=-\frac{\partial P}{\partial x}+\mu\left(\frac{\partial^{2} u}{\partial x^{2}}+\frac{\partial^{2} u}{\partial y^{2}}\right) \\
& \rho\left(u \frac{\partial v}{\partial x}+v \frac{\partial v}{\partial y}\right)=-\frac{\partial P}{\partial y}+\mu\left(\frac{\partial^{2} v}{\partial x^{2}}+\frac{\partial^{2} v}{\partial y^{2}}\right)
\end{aligned}
$$

olarak verilmiştir [10]. Enerji denklemleri ise;

$$
\begin{gathered}
\rho \mathrm{C}_{\mathrm{p}}\left(\mathrm{u}_{\mathrm{x}} \frac{\partial \mathrm{T}}{\partial \mathrm{x}}+\mathrm{u}_{\mathrm{y}} \frac{\partial \mathrm{T}}{\partial \mathrm{y}}\right)=\mathrm{k}\left[\frac{\partial^{2} \mathrm{~T}}{\partial \mathrm{x}^{2}}+\frac{\partial^{2} \mathrm{~T}}{\partial \mathrm{y}^{2}}\right] \\
+2 \mu\left\{\left(\frac{\partial \mathrm{u}_{\mathrm{x}}}{\partial \mathrm{x}}\right)^{2}+\left(\frac{\partial \mathrm{u}_{\mathrm{y}}}{\partial \mathrm{y}}\right)^{2}\right\}+\mu\left(\frac{\partial \mathrm{u}_{\mathrm{x}}}{\partial \mathrm{y}}+\frac{\partial \mathrm{u}_{\mathrm{y}}}{\partial \mathrm{x}}\right)^{2}
\end{gathered}
$$

şeklinde tanımlanmaktadır [11]. Bağımsız değişkenler boyutsuzlaştırılırsa;

$$
\mathrm{x}^{*} \equiv \frac{\mathrm{x}}{\mathrm{L}} \quad \text { ve } \quad \mathrm{y}^{*} \equiv \frac{\mathrm{y}}{\mathrm{L}}
$$


şeklinde ifade edilir. Burada, L ısı değiștiricinin karakteristik uzunluğudur. Ayrıca V, akışkanın yüzeye gelmeden önceki hızı olmak üzere aşağıdaki bağımlı değişkenler tanımlanabilir [12];

$$
\begin{gathered}
\mathrm{u}^{*} \equiv \frac{\mathrm{u}}{\mathrm{V}} \quad \text { ve } \quad \mathrm{v}^{*} \equiv \frac{\mathrm{v}}{\mathrm{V}} \\
\mathrm{T}^{*} \equiv \frac{\mathrm{T}-\mathrm{T}_{\mathrm{s}}}{\mathrm{T}_{\infty}-\mathrm{T}_{\mathrm{s}}}
\end{gathered}
$$

Burada $\mathrm{T}_{\infty}$ ısı değiștiricinin bulunduğu ortam sıcaklığı, $\mathrm{T}_{\mathrm{s}}$ akışkanın ısı değiştirici ile temas ettiği yüzey sıcaklığıdır. Bu değerler (1), (2), (3) ve (4) denklemlerine uyarlanırsa;

$$
\begin{gathered}
\frac{\partial \mathrm{u}^{*}}{\partial \mathrm{x}^{*}}+\frac{\partial \mathrm{v}^{*}}{\partial \mathrm{y}^{*}}=0 \\
\mathrm{u}^{*} \frac{\partial \mathrm{u}^{*}}{\partial \mathrm{x}^{*}}+\mathrm{v}^{*} \frac{\partial \mathrm{v}^{*}}{\partial \mathrm{y}^{*}}=\left(-\frac{\mathrm{dp}^{*}}{\mathrm{dx}^{*}}+\frac{1}{\operatorname{Re}_{\mathrm{L}}} \frac{\partial^{2} \mathrm{u}^{*}}{\partial \mathrm{y}^{*^{2}}}\right) \\
+\left(-\frac{\mathrm{dp}^{*}}{\mathrm{dy}^{*}}+\frac{1}{\mathrm{Re}_{\mathrm{L}}} \frac{\partial^{2} \mathrm{v}^{*}}{\partial \mathrm{x}^{*}}\right)
\end{gathered}
$$

şeklinde elde edilir. Enerji denklemi ise;

$$
\mathrm{u}^{*} \frac{\partial \mathrm{T}^{*}}{\partial \mathrm{x}^{*}}+\mathrm{v}^{*} \frac{\partial \mathrm{T}^{*}}{\partial \mathrm{y}^{*}}=\frac{1}{\operatorname{Re}_{\mathrm{L}} \operatorname{Pr}} \frac{\partial^{2} \mathrm{~T}^{*}}{\partial \mathrm{y}^{*^{2}}}+\frac{1}{\mathrm{Re}_{\mathrm{L}} \operatorname{Pr}} \frac{\partial^{2} \mathrm{~T}^{*}}{\partial \mathrm{x}^{*^{2}}}
$$

şeklinde elde edilir. Isı değiştiriciden geçen akışkanın türbülanslı olması sebebiyle Reynolds sayısının etkisi N-S denklemlerinde görüldügü gibidir. Yukarıdaki Reynolds Average Navier-Stokes (RANS) denklemleri içindeki terimlerin Reynolds sayllarına göre etkinlikleri isı transferinde önemli bir parametre olarak görülmektedir. RANS denklemleri içerisindeki $\mathrm{Re}_{\mathrm{L}}$

$$
\operatorname{Re}_{\mathrm{L}} \equiv \frac{\mathrm{VL}}{v}
$$

şeklinde ifade edilmiştir [12]. Ayrıca Pr;

$$
\operatorname{Pr} \equiv \frac{\mathrm{v}}{a}
$$

şeklinde tanımlanmıştır [12].

Çalışma için birinci ısı değiştiricide (Model A) bütün yüzeyler düz (desensiz), ikincide ise (Model B) sadece alt ve üst yüzeyleri diyagonal desenli tasarlanmıştır (Şekil 1). Model A'nın genişliği $W=200 \mathrm{~mm}$, yüksekliği $\mathrm{H}=40 \mathrm{~mm}$ ve uzunluğu $\mathrm{L}=1077,9 \mathrm{~mm}$, Model B'nin genişliği $\mathrm{W}=200 \mathrm{~mm}$, yüksekliği $\mathrm{H}=40$ mm ve uzunluğu $\mathrm{L}=1000 \mathrm{~mm}$ tasarlanmıștır. Model B'nin sadece alt ve üst yüzeylerinde köşegen uzunlukları $50 \mathrm{~mm}$ ve derinlikleri $9 \mathrm{~mm}$ olan diyagonal desenler bulunmaktadır (Şekil 2). Model A ve B'nin yüzey alanlarının eşit olması için, uzunlukları (L) birbirinden farklı tasarlanmıştır. $\mathrm{Bu}$ sayede, yüzeylerden kaynaklanan ısı transfer miktarlarındaki kıyaslamada yüzey alanının etkisinin olmaması sağlanmıştır. Model A ve B'nin toplam yüzey alanları $0,517 \mathrm{~m}^{2}$ olarak programdan elde edilmiștir.

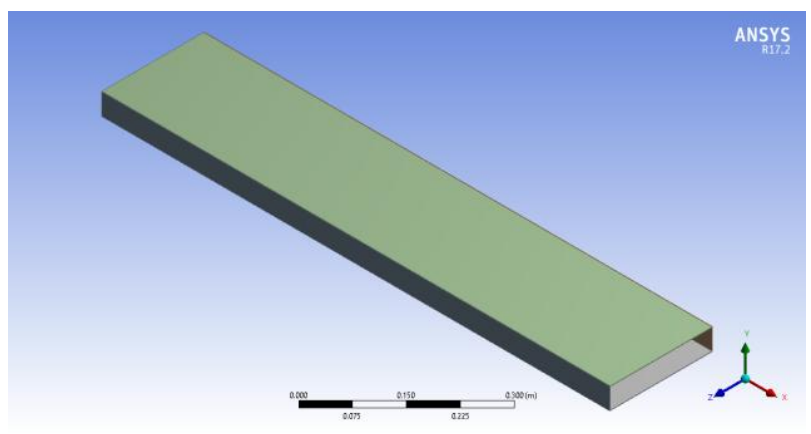

(a)

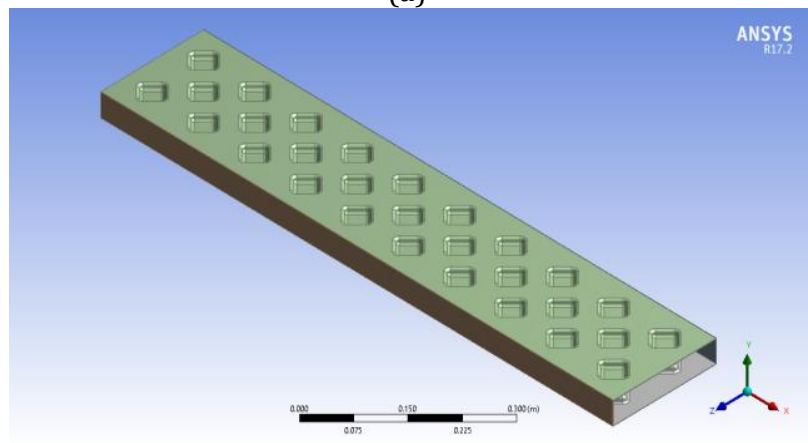

(b)

Şekil 1. Isı değiştiricilerin perspektif görünüşleri (a) Model A (b) Model B

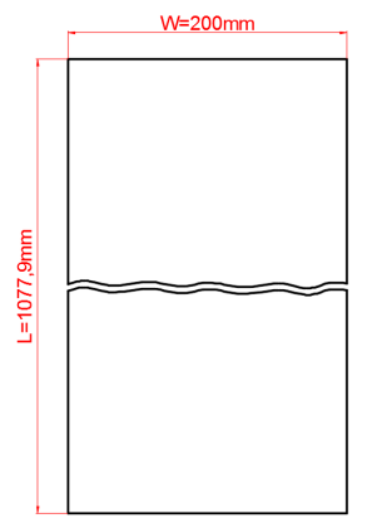

(a)

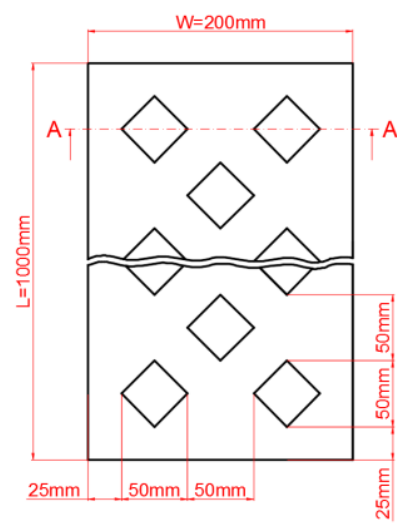

(c)

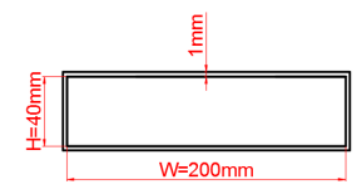

(b)

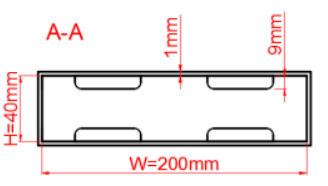

(d)
Şekil 2. Isı değiștiricilerin 2-D görünüșü ve boyutları (a) Model A üst görünüş (b) Model A ön görünüş (c) Model B üst görünüş (d) Model B A-A kesit görünüş 
Model A ve B'nin ağ yapısının oluşturulması için "Tetrahedrons Method Without Inflation" metodu kullanılmıștır. Oluşturulacak ağ yapısının element sayısının belirlenmesi için meshten bağımsızlık testi yapılmış ve element sayısına göre çıkıştaki hava sıcaklıkları elde edilmiştir (Şekil 3). Element sayısı Model A'da 46465'ten, Model B'de 2252876'dan sonrası için çıkış sıcaklıklarının değişmemesi sebebiyle simülasyon için bu değerler kullanılmıştır. Buna doğrultuda, Model A'nın ağ yapısı 10096 düğüm noktasından ve 46465 elementten oluşmuştur. A $\breve{g}$ yapısının element kalitesi ortalama 0.83219 ve skewness değeri ortalama 0.23446 okunmuştur. Model B'nin ağ yapısı 432051 düğüm noktasından ve 2252876 elementten oluşmuştur. A $\breve{g}$ yapısının element kalitesi ortalama 0.83491 ve skewness değeri ortalama 0.23205 okunmuştur. Element kalitesinin 0 ve 1 aralığından 1'e yakın olması, kalitesinin yüksek olduğunu göstermektedir. Skewness değeri ise 0 ve 1 aralığından 0'a yaklaştıkça daha kaliteli olmaktadır [13]. Model A ve B için element kalitesi ve skewness değerinin belirtilen aralıklarda ve uygun değerlerde olduğu görülmektedir. Ağ yapısı oluşturulan ısı değiştiricileri Şekil 4'te görülmektedir.

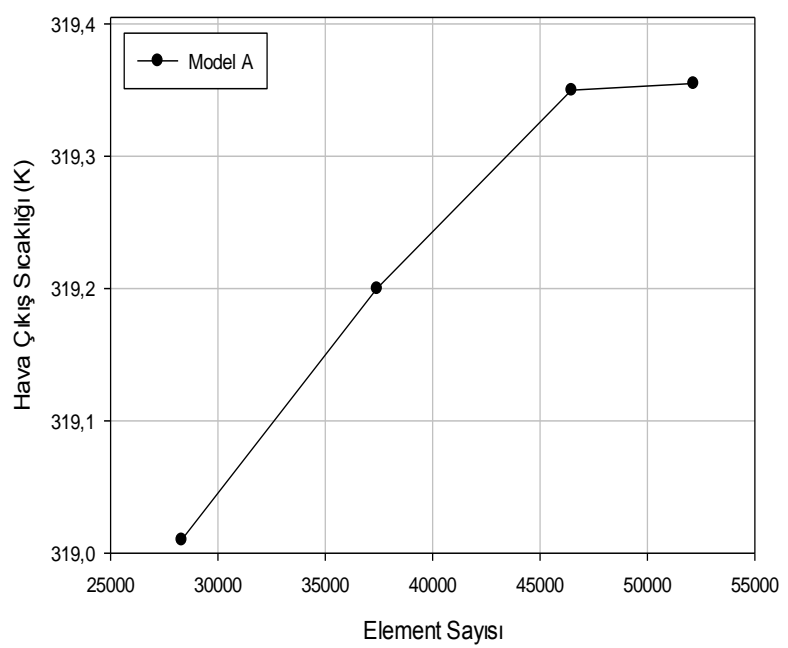

(a)

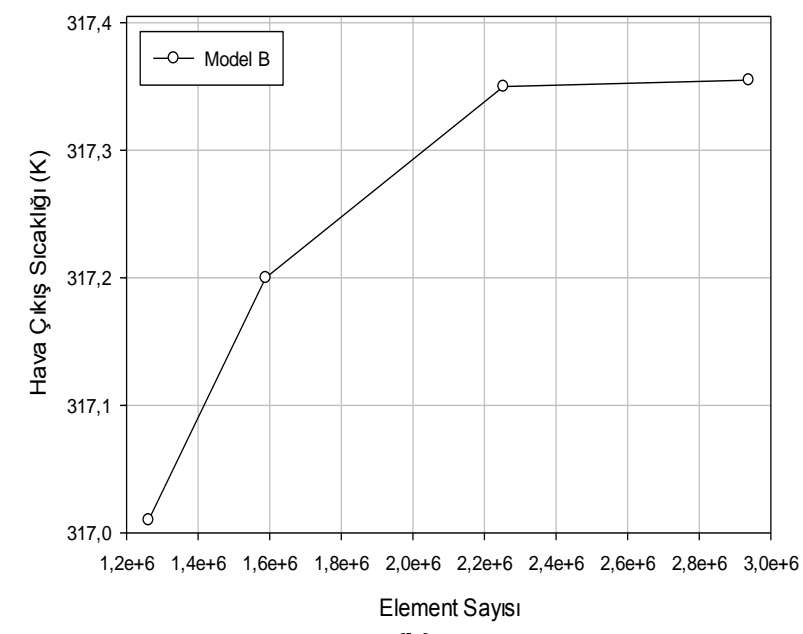

(b)

Şekil 3. Element sayısına bağlı hava çıkıș sıcaklığı (a) Model A, (b) Model B

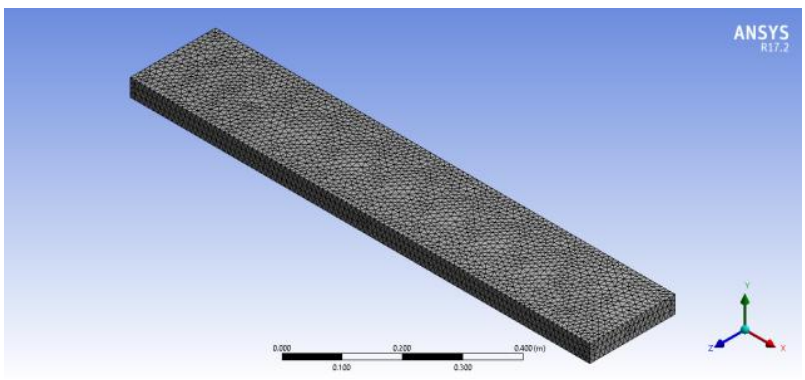

(a)

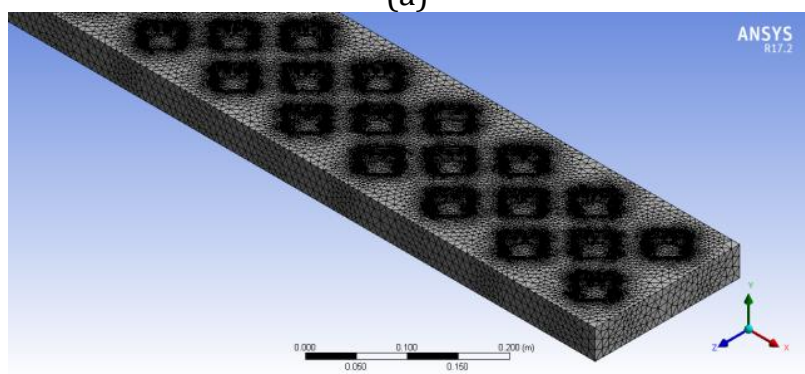

(b)

Şekil 4. Ağ yapısının genel görünüşü (a) Model A (b) Model B

Isı değiștiricinin yüzeyine eklenen diyagonal desenlerin ısı transferine etkisini incelemek için hava kullanılmıștır. Model A ve B'ye giren havanın yoğunluğu $1.225 \mathrm{~kg} / \mathrm{m}^{3}$, Pr sayısı 0.744 , ısı iletim katsayısı $0.0242 \mathrm{~W} / \mathrm{mK}^{\prime}$ dir [13]. Havanın sıcaklığı ve basıncı ise sirasıyla $335.05 \mathrm{~K}$ ve $101325 \mathrm{~Pa}$ olarak belirlenmiştir. $\mathrm{Bu}$ parametreler sabit tutularak 6 farklı kütlesel debi için $(0.004,0.006,0.008,0.010$, $0.012,0.014 \mathrm{~kg} / \mathrm{s}$ ) çözümler yapılmıştır. Isı değiştirici malzemesi olarak çelik kullanılmıştır. Kullanılan çeliğin yoğunluğu $8030 \mathrm{~kg} / \mathrm{m}^{3}$, ısı iletim katsayısı $16.27 \mathrm{~W} / \mathrm{mK}$ ve radyasyon yayma oranı $\varepsilon=0.21$ 'dir [13]. Isı değiştiricilerin bulunduğu ortamdaki havanın sıcaklığı 293.5 K, basıncı $101325 \quad \mathrm{~Pa}$ olarak belirlenmiştir.

Isı değiştiricilerinin çeperlerinden atmosfere doğal konveksiyon ve radyasyon yolu ile isı transferi meydana gelmektedir. Bu değerlerin nümerik olarak hesaplanabilmesi için ısı değiștiricilerin çevresindeki doğal konveksiyon taşınım katsayılarının bilinmesi gerekmektedir. Doğal konveksiyon için N-S denklemlerinin yer çekimi vektörü üzerindeki bileșenini dikkate alarak aşağıdaki boyutsuz büyüklüklerle hesaplanmaktadır;

$$
\begin{gathered}
\mathrm{x}^{*} \equiv \frac{\mathrm{x}}{\mathrm{L}} \quad \text { ve } \quad \mathrm{y}^{*} \equiv \frac{\mathrm{y}}{\mathrm{L}} \\
\mathrm{u}^{*} \equiv \frac{\mathrm{u}}{\mathrm{u}_{0}} \quad \text { ve } \quad \mathrm{v}^{*} \equiv \frac{\mathrm{v}}{\mathrm{u}_{0}} \\
\mathrm{~T}^{*} \equiv \frac{\mathrm{T}-\mathrm{T}_{\infty}}{\mathrm{T}_{\mathrm{s}}-\mathrm{T}_{\infty}}
\end{gathered}
$$

Burada L karakteristik uzunluğu, $\mathrm{u}_{0}$ herhangi bir referans akışkan hızını, $\mathrm{T}_{\infty}$ doğal konveksiyona maruz kalan ısı değiștiricinin bulunduğu ortam sıcaklığı, $\mathrm{T}_{\mathrm{s}}$ akışkanın ısı değiştirici ile temas ettiği 
yüzey sıcaklığını göstermektedir [12]. Yukarıdaki boyutsuz ifadeleri yer çekimi vektörüne paralel eksen üzerindeki N-S denklemlerine uyarlanırsa;

$$
\mathrm{u}^{*} \frac{\partial \mathrm{T}^{*}}{\partial \mathrm{x}^{*}}+\mathrm{v}^{*} \frac{\partial \mathrm{T}^{*}}{\partial \mathrm{y}^{*}}=\frac{1}{\operatorname{Re}_{\mathrm{L}} \operatorname{Pr}} \frac{\partial^{2} \mathrm{~T}^{*}}{\partial \mathrm{y}^{*^{2}}}
$$

șeklinde elde edilir. Doğal taşınımda serbest akıș bölgesi için durgun olduğundan, zorlanmış taşanımda olduğu gibi $\mathrm{V}$ veya $\mathrm{u}_{\infty}$ gibi anlamlı bir dış referans tanımlamak zordur. $\mathrm{Bu}$ nedenle daha pratik bir yaklaşım olarak Grashof (Gr) ifadesi kullanılır. Bu ifade;

$$
\mathrm{Gr}_{\mathrm{L}} \equiv \frac{\mathrm{g} \beta\left(\mathrm{T}_{\mathrm{s}}-\mathrm{T}_{\infty}\right) \mathrm{L}^{3}}{\mathrm{v}^{2}}
$$

şeklindedir. Buna göre isı değiştiricinin yüzeylerindeki doğal taşınım katsayısı $\mathrm{Gr}_{\mathrm{L}}$ ile $\mathrm{Pr}$ sayısının çarpımından elde edilen Rayleigh sayısına göre hesaplanabilir [12]. Analitik olarak hesaplanan doğal konveksiyon taşınım katsayıları ve Reynolds sayıları Tablo 1'de verilmiştir. Tablo 1'deki Reynolds sayıları incelendiğinde bütün debilerde akışın türbülanslı olduğu görülmektedir. Bu sebepten dolayı çalışmada "K- $\varepsilon$, RNG, Standart Wall" türbülans modeli tercih edilmiştir.

\begin{tabular}{|c|c|c|c|}
\hline & 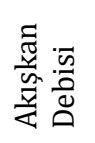 & 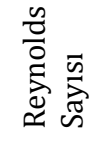 & 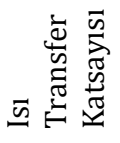 \\
\hline & $\mathrm{kg} / \mathrm{s}$ & & $\mathrm{W} / \mathrm{m}^{2} \mathrm{~K}$ \\
\hline \multirow{6}{*}{ Model A } & 0.004 & 4269 & 4.79 \\
\hline & 0.006 & 6404 & 4.90 \\
\hline & 0.008 & 8539 & 4.95 \\
\hline & 0.010 & 10673 & 4.99 \\
\hline & 0.012 & 12808 & 5.01 \\
\hline & 0.014 & 14942 & 5.04 \\
\hline \multirow{6}{*}{ Model B } & 0.004 & 4269 & 4.94 \\
\hline & 0.006 & 6404 & 5.05 \\
\hline & 0.008 & 8539 & 5.10 \\
\hline & 0.010 & 10673 & 5.13 \\
\hline & 0.012 & 12808 & 5.16 \\
\hline & 0.014 & 14942 & 5.19 \\
\hline
\end{tabular}

Tablo 1. Analitik olarak hesaplanan parametreler

\section{Araştırma Bulguları ve Tartışma}

Model A ve B'ye 335.05 K sıcaklığında altı farklı kütlesel debide giren hava için nümerik çözümler yapılmıştır. Çözümlerde ısı değiştiricilerinden geçen havanın çıkış sıcaklıkları, eksenel uzunluk boyunca hız değişimleri, akış alanı ve basınç değişimi gibi parametreler ve bu parametrelerde yüzeye eklenen diyagonal desenin etkisi incelenmiştir. Havanın nümerik çözümle elde edilen çıkış sıcaklıkları ve ısı geçiş oranları Tablo 2'de verilmiştir. Havanın çıkış sıcaklık değerlerinin kütlesel debinin artışı ile arttığı görülmektedir (Şekil 5).

\begin{tabular}{|c|c|c|c|}
\hline & 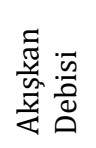 & 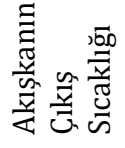 & 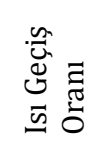 \\
\hline & $\mathrm{kg} / \mathrm{s}$ & $\mathrm{K}$ & $\mathrm{W} / \mathrm{m}^{2}$ \\
\hline \multirow{6}{*}{ Model A } & 0.004 & 319.35 & 122.35 \\
\hline & 0.006 & 323.40 & 136.02 \\
\hline & 0.008 & 325.80 & 143.01 \\
\hline & 0.010 & 327.37 & 149.89 \\
\hline & 0.012 & 328.48 & 152.76 \\
\hline & 0.014 & 329.27 & 157.89 \\
\hline \multirow{6}{*}{ Model B } & 0.004 & 317.37 & 136.24 \\
\hline & 0.006 & 321.45 & 158.13 \\
\hline & 0.008 & 323.99 & 171.25 \\
\hline & 0.010 & 325.72 & 180.54 \\
\hline & 0.012 & 326.96 & 187.25 \\
\hline & 0.014 & 327.89 & 193.02 \\
\hline
\end{tabular}

Tablo 2. Havanın çıkıș sıcaklıkları

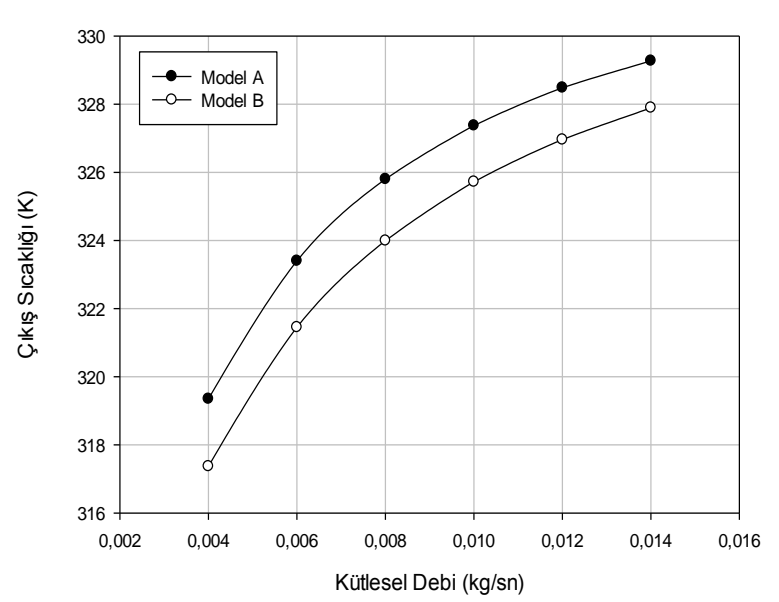

Şekil 5. Model A ve B için havanın çıkış sıcaklıklarının debiye göre değişimi

Hem Model A hem de Model B'de havanın kütlesel debisinin artmasıyla çıkıș sıcaklık değerleri de artmaktadır. $\mathrm{Bu}$ artış üstel fonksiyon şeklindedir. Literatürde, ısı değiştiricilerinin çeperlerinden ortama doğal konveksiyon yolu ile transfer edilen isı miktarı, ortam ile temaslı yüzey sıcaklık değerlerinin "n" üstel fonksiyonu ile $\left(\mathrm{Q} \propto \mathrm{T}_{\mathrm{s}}^{\mathrm{n}}\right)$ orantılı olarak değiştiğinden, orantıdaki üst kuvvetin doğal konveksiyon için, " $n$ " değerinin 1.25-1.33 değerleri arasında olduğundan bahsedilmektedir [10]. Bu literatür bilgisine göre, ısı değiștiricinin diş yüzeyinden atmosfere transfer edilen isı miktarı " $Q$ " 'nun üstel fonksiyon halinde değişimi gerçekleşeceğinden dolayı, hem Model A hem de Model B'deki ısı değiştiricilerinden 6 farklı kütlesel debinin değişiminden elde edilen isı miktarı, $\dot{\mathrm{Q}}=\dot{\mathrm{m}} \mathrm{cp} \Delta \mathrm{T}$ formülü ile sicaklık farkı olan $\Delta \mathrm{T}^{\prime}$ nin de üstel fonksiyon halinde değiștiği görülmektedir.

Model A ve B'deki çıkış sıcaklık değerleri karşılaștırıldığında; Model A'nın çıkıș sıcaklık değerlerinin Model B'nin çıkış sıcaklık değerinden yüksek olduğu görülmektedir. Model A'daki havanın çıkış sıcaklık değerinin yüksek olması, aynı veriler altında kanal içerisinden geçirilen sıcak havanın kanalın çeperlerinden ortama olan ısı transferinin az 
olmasından dolayıdır. Model A ve B'nin içerisinden başlangıç şartları ve sınır şartları aynı kalmak koşuluyla kütlesel debisi $\dot{\mathrm{m}}=0.004 \mathrm{~kg} / \mathrm{s}$ değerinde sıcak hava geçirildiğinde, isı değiștiricinin üst yüzeyindeki sıcaklık dağılımı Şekil 6'da gösterilmiştir.

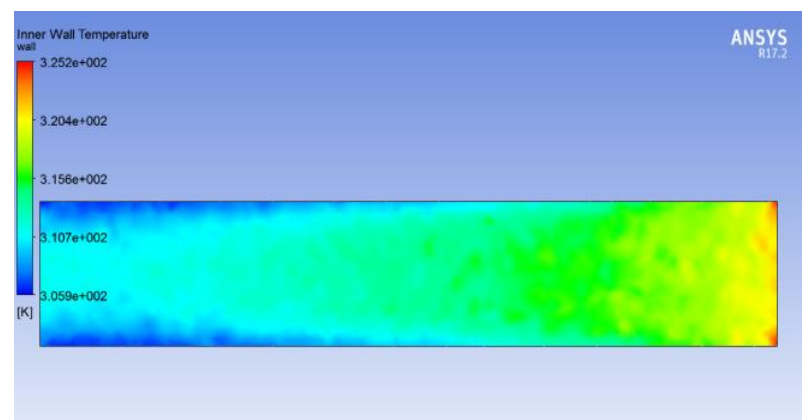

(a)

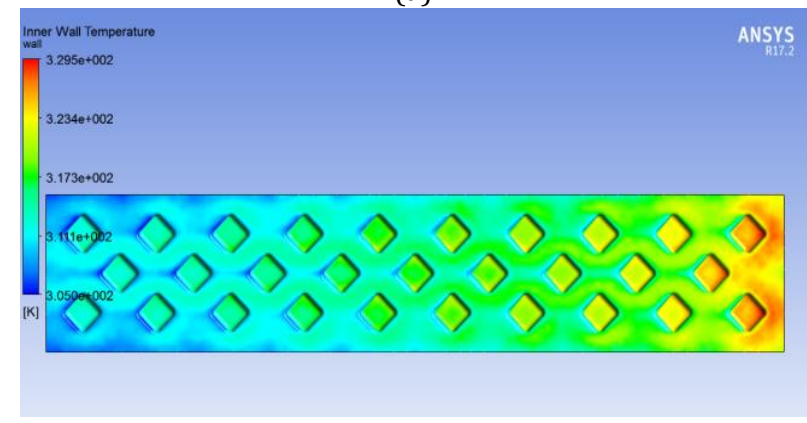

(b)

Şekil 6. Isı değiştiricilerinin hava ile temas ettiği üst iç duvar yüzey sıcaklık dağılımlarının görünüşü (a) Model A (b) Model B

Şekil 6 incelendiğinde; ısı değiștiricinin üst yüzeyinin sıcaklık dağılımının içerisinde maksimum sıcaklık değeri Model A'da 325.2 K iken, Model B'de 329.5 K olduğu görülmektedir. Model B'nin üst iç yüzey sıcaklığının fazla olmasından dolayı bu yüzeyden ortama olan ısı transferinin Model A'ya göre yüksek olduğu ifade edilebilir. Ayrıca Model B'deki yüksek sıcaklık alanları Model A'daki yüksek sıcaklık alanlarından daha fazladır. Model B'deki alt ve üst yüzeylerde birbirlerine simetrik diyagonal desenlerin etkisi ile ısı değiştiricinin içerisinden geçirilen sıcak havanın akıșı sırasında türbülanslı sınır tabaka kalınlığının desenler arasında daha da inceldiğinin ve bu incelme ile birlikte türbülanslı sınır tabakaya dalgalı implus alış-veriş sağladığı Model A ve Model B'deki yüzeysel sıcaklık dağılımında görülmektedir.

Analitik olarak Model A ve B'nin çeperlerinden ortama konveksiyon ve radyasyon yolu ile gerçekleşen toplam isı transfer miktarı ( $\mathrm{Q}_{\text {Toplam }}$ ) denklem (18)'e göre hesaplanır. Model B'deki yüzeysel sicaklı değişimi $(\mathrm{dT} / \mathrm{dx})_{\mathrm{y}=\text { sabit }}$ değerlerindeki bölgesel farklılıklardan dolayı gerçek toplam isı transferini analitik yol ile hesaplamak oldukça zordur. Bu sebepten çeperlerdeki doğal konveksiyon ve radyasyon yolu ile gerçekleşen toplam isı transferi değerleri nümerik olarak hesaplanmıș, Model A ve B için Tablo 3'de verilmiștir. Ayrıca çeperlerdeki toplam ısı transferinin debiye göre değişimi Şekil 7'de verilmiştir.

$$
\begin{aligned}
& \underbrace{Q_{\mathrm{T}}}_{\begin{array}{c}
\text { Toplam } \\
\text { Isı } \\
\text { Kaybı }
\end{array}}=\underbrace{Q_{\text {Konveksiyon,Dikey }}^{Q_{\text {Ist }}}}_{\begin{array}{c}
\text { 2 Dikey Duvardaki } \\
\text { Konveksiyonla } \\
\text { Isı Kaybı }
\end{array}}+\underbrace{Q_{\text {Konveksiyon,Üst }}}_{\begin{array}{c}
\text { Üst Duvardaki } \\
\text { Konveksiyonla } \\
\text { Isı Kaybı }
\end{array}} \\
& +\underbrace{Q_{\text {Konveksiyon,Alt }}}_{\text {Alt Duvardaki }}+\underbrace{Q_{\text {Radyasyon,Dikey }}}_{\text {2 Dikey Duvardaki }} \\
& \begin{array}{c}
\text { Konveksiyonla } \\
\text { Isı Kaybı }
\end{array} \\
& +\underbrace{Q_{\text {Radyasyon,Üst }}}_{\begin{array}{c}
\text { Üst Duvardaki } \\
\text { Radyasyonla } \\
\text { Isı Kaybı }
\end{array}}+\underbrace{Q_{\text {Radyasyon,Alt }}}_{\begin{array}{c}
\text { Alt Duvardaki } \\
\text { Radyasyonla } \\
\text { Isı Kaybı }
\end{array}}
\end{aligned}
$$

\begin{tabular}{|c|c|c|c|c|c|}
\hline & 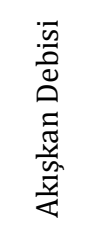 & 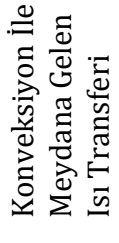 & 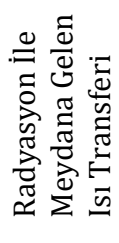 & 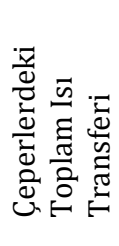 & $\begin{array}{l}\stackrel{y}{\vec{\pi}} \\
\text { I }\end{array}$ \\
\hline & $\mathrm{kg} / \mathrm{s}$ & W & $\mathrm{W}$ & W & $\%$ \\
\hline \multirow{6}{*}{ Model A } & 0.004 & 49.44 & 13.71 & 63.15 & - \\
\hline & 0.006 & 55.19 & 15.10 & 70.29 & - \\
\hline & 0.008 & 58.50 & 15.92 & 74.42 & - \\
\hline & 0.010 & 60.78 & 16.44 & 77.22 & - \\
\hline & 0.012 & 62.42 & 16.86 & 79.28 & - \\
\hline & 0.014 & 64.17 & 17.23 & 81.40 & - \\
\hline \multirow{6}{*}{ Model B } & 0.004 & 55.54 & 15.11 & 70.65 & 11.9 \\
\hline & 0.006 & 64.20 & 17.32 & 81.52 & 16.0 \\
\hline & 0.008 & 69.64 & 18.76 & 88.40 & 18.8 \\
\hline & 0.010 & 73.45 & 19.78 & 93.23 & 20.7 \\
\hline & 0.012 & 76.44 & 20.55 & 96.99 & 22.3 \\
\hline & 0.014 & 78.90 & 21.17 & 100.07 & 22.9 \\
\hline
\end{tabular}

Tablo 3. Çeperlerdeki ısı transferi değerleri

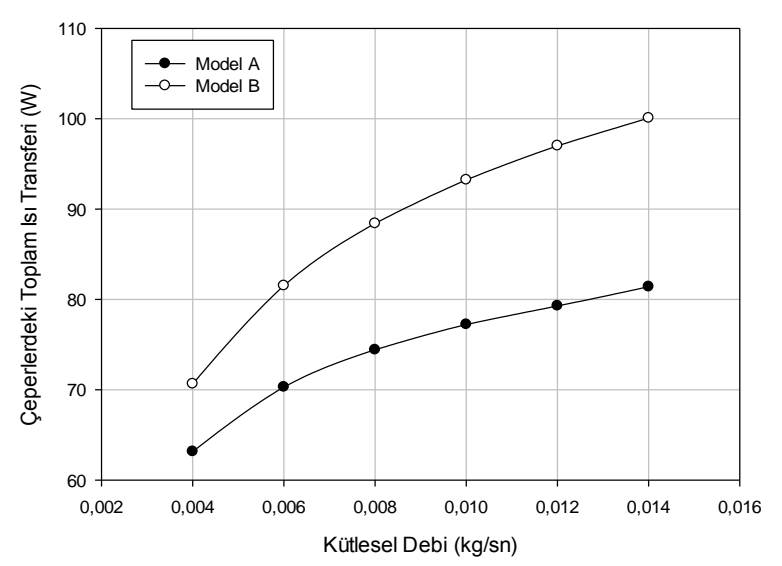

Şekil 7. Çeperlerdeki toplam ısı transferin debiye göre değişimi

Model B'deki diyagonal desenlerin neden olduğu sıcaklık dağılımlarından dolayı Model B'deki toplam Isı transfer değeri Model A'ya göre büyük çıkmıștır. Transfer olan ısı miktarları, ısı değiștiricinin dış yüzey sıcaklıklarına bağlıdır. $\mathrm{Bu}$ bağlılık önceki paragraflarda anlatıldığı gibi transfer edilen ısı miktarı duvarların dış yüzeysel sıcaklık değerlerinin " $n$ " üstel fonksiyonu $\left(Q \propto T_{\mathrm{s}}^{\mathrm{n}}\right)$ ile orantılı olup; Model B'deki " $n$ " üst kuvvet değeri Model A'daki üst kuvvet değerinden büyüktür. Bu büyüklük değeri Şekil 7'de de görülmektedir. Model A ve B'de transfer edilen ısı miktarlarının farkı Model B'nin alt ve üst yüzeylerindeki 58 adet diyagonal desenden meydana 
gelmiştir. Kütlesel debi değeri arttıkça Model A ve B'de transfer edilen ısı miktarı farkı da giderek artmaktadır (Tablo 3). Bunun sebebi; daha önce belirtilen türbülanslı sınır tabaka kalınlığının giderek azalması ve bu azalmış halini koruyabilmek için sınır tabakaya implus alış-verişini kütlesel debinin artışıyla sağlamasıdır. Bunun sonucunda ise diyagonal desenli bölgelerde ısı alış-verişi yükselmektedir. Tablo 3'teki toplam ısı transferi ile Tablo2'deki ısı geçiş oranları karşılaştırıldığında; ısı değiştirici içerisinden geçen havanın yüzeylere bıraktığı ısı ile çeperlerden meydana gelen isı transferi değerlerinin birbirleriyle uyumlu olduğu ve enerji korunumunun sağlandığı görülmektedir.

Isı değiștiricilerindeki akış hızı ve alanını incelemek için giriş bölgesi de dahil sekiz farklı nokta belirlenmiştir (Şekil 8). Bu noktalarda kanalın alt ve üst yüzerleri ile temas eden bir çizgi üzerindeki hız profilleri $\dot{\mathrm{m}}=0.004 \mathrm{~kg} / \mathrm{s}$ kütlesel debisi için çizdirilmiştir (Şekil 9).

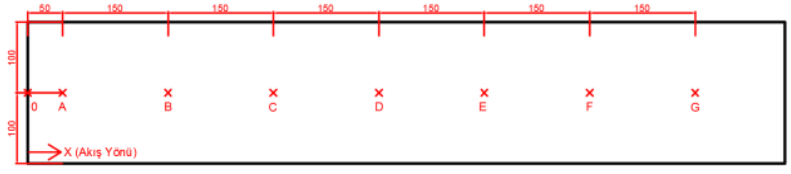

(a)

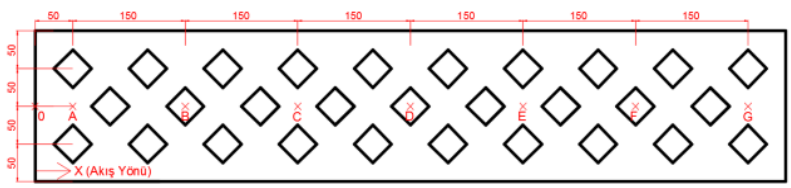

(b)

Şekil 8. Hız grafiklerinin çizdirildiği konumlar (a) Model A (b) Model B

Şekil 9 incelendiğinde; Model A ve B'deki akışların tamamı türbülanslı olduğundan akıș hızı kanal ortasından kanal kenarına yakın bir bölgeye kadar sabit kalmaktadır. Konum 0'daki maksimum sabit hız değeri süreklilik denkleminin uyarlanmasıyla elde edilen hız değerlerinden düşüktür. Lindeburg (2013) ve Mohammedsalih (2017) tarafindan yapılan araştırmalarda ısı değiştirici içerisinden geçirilen sıcak hava akışının ortalama hızını veren bir denklem ile deneysel çalışmalara daha yakın değerler elde edildiğini ifade etmişlerdir. Bu denklem;

$$
\mathrm{V}_{\text {ort }}=\frac{49}{60} \mathrm{~V}_{\max }
$$

şeklindedir [14], [15]. Denklem (19) çalışmaya uyarlandığında; $\quad \mathrm{V}_{\text {ort }}=0.870 \mathrm{~m} / \mathrm{s} \quad$ çıkmaktadır. Nümerik çalışmada ise $\mathrm{V}_{\text {ort }}=0.940 \mathrm{~m} / \mathrm{s}$ bulunmuştur. Bu değer dikkate alınarak hesaplanan ısı değiştiriciden geçen sıcak kaybettiği ısı miktarı ile ısı değiştiricinin yüzeyinden ortama olan doğal konveksiyon yolu ile kaybedilen ısı miktarları birbirlerine yakın çıkmıştır. Ayrıca havanın ısı değiştirici içerisinden geçerken nümerik olarak elde edilen hiz profillerinde de bir uyumluluk görüşmüştür.
$\mathrm{Bu}$ profillerin birbiriyle uyumlu olması nedeniyle bu çalışmada da $\mathrm{V}_{\text {ort }}$ değerinin geçerli olduğu görülmüștür. $\mathrm{Bu}$ konumda Model $\mathrm{A}$ ve $\mathrm{B}$ 'nin $\mathrm{V}_{\text {ort max }}$ değerleri karşılaştırıldığında; Model A'daki değerinin Model B'ninkinden az da olsa yüksek olduğu görülmektedir. Hava Model B'nin alt ve üst yüzeylerindeki diyagonal desenlerin olduğu bölgeye gelmeden önce hızı ve dolayısıyla kinetik enerjisi küçüktür. Kinetik enerjinin düşük olması enerjinin korunumu denklemine göre basınç enerjisinin yüksek olmasına neden olmaktadır. Bu sebepten Model B'nin 0 konumundaki hızının Model A'dan düşük olması beklenen bir durumdur.

Şekil 9'da Model A'ya ait hız profillerinde fazla bir değișiklik görülmemektedir. Isı değiștirici içinde ilerleyen akışkanın doğrultusu boyunca $V_{\text {ort max }}$ değeri artmaktadır. $\mathrm{Bu}$ artış havanın hidrodinamik açıdan tam gelişmesine kadar devam etmektedir. Isı değiştirici içerisinde giriş noktasından çıkış noktasına kadar merkezinde bir çizgi boyunca hız profili Şekil 10 'da verilmiștir. Model A' için hidrodinamik tam gelişmenin oluşmadığı görülmektedir. Hidrodinamik tam gelişme bölgesi analitik olarak hesaplandığında 6.5 m'den sonra gerçekleşecektir.

Model B'ye ait hiz profilleri incelendiğinde; desenlerin arasından geçen havanın akış hızı süreklilik denklemine uyarak, desensiz bölgelerdeki hızından yüksektir (Şekil 9). Ayrıca havanın desenler sayesinde hidrodinamik olarak geliştiği görülmektedir (Şekil 9 ve Şekil 10). Girișten sonra ilk gelen diyagonal desen önüne kadar basınç enerjisinin yüksek olduğu ve bu bölgeden sonra basıncın yavaş yavaş kinetik enerjiye dönüşmeye başlamaktadır. Tam desenler arasında ise kinetik enerjinin en yüksek değere ulaştığı, daha sonra yine kinetik enerji azalması ile birlikte basınç enerjisinin yükselmesine sebep olmaktadır.

Model B'deki diyagonal desenlerin bulunduğu bölgelerde, havanın ilerleyişini incelemek için, ısı değiștiricinin üst yüzeyinin $1 \mathrm{~mm}$ altından $(\mathrm{H}=39$ $\mathrm{mm}$ ) geçen yatay düzlemdeki hız alanları $\dot{\mathrm{m}}=0,004$ $\mathrm{kg} / \mathrm{s}$ kütlesel debisi için Şekil 11'de verilmiştir.

Isı değiştirici içerisinden geçen havanın, ısı değiştirici duvar yüzeyleri üzerindeki hızı " 0 " alınarak nümerik çözüm yapılmıştır. Bundan dolayı, havanın desen yüzeyi ile temas ettiği bölgelerde akış iplikçikleri görülmemektedir. Bununla birlikte kütlesel debinin korunumu denklemine uyularak desenler ile isı değiștiricinin dikey duvarlarına yakın bölgelerde akış iplikçiklerinin yoğunlaştığı görülmektedir. Ayrıca diyagonal desenin gövde kısımları ile ısı değiştiricinin dikey duvarları arasındaki bölgelerde de akış iplikçiklerinin yoğunlaştığı görülmektedir. Hava akışı boyunca diyagonal desenin burun kismına yaklaşırken, burun uç kısmı, burun bölgesi ve desen gövdesine kadar kinetik enerjinin artarak, basınç enerjisinde azalarak ilerlediği bilinmektedir. 


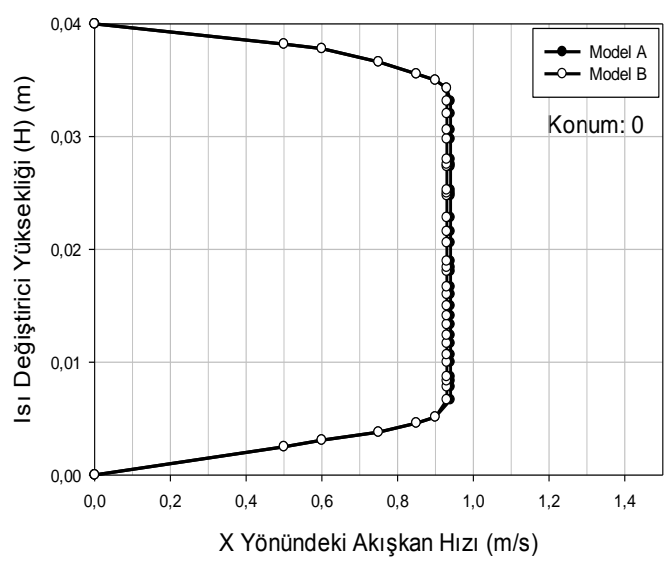

(a)

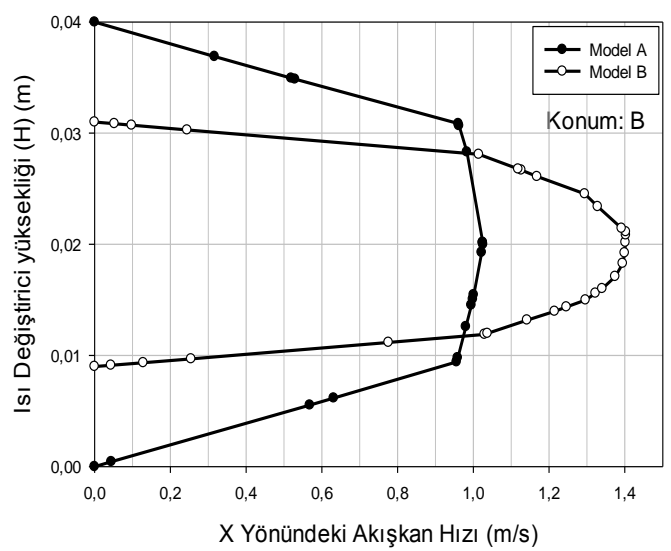

(c)

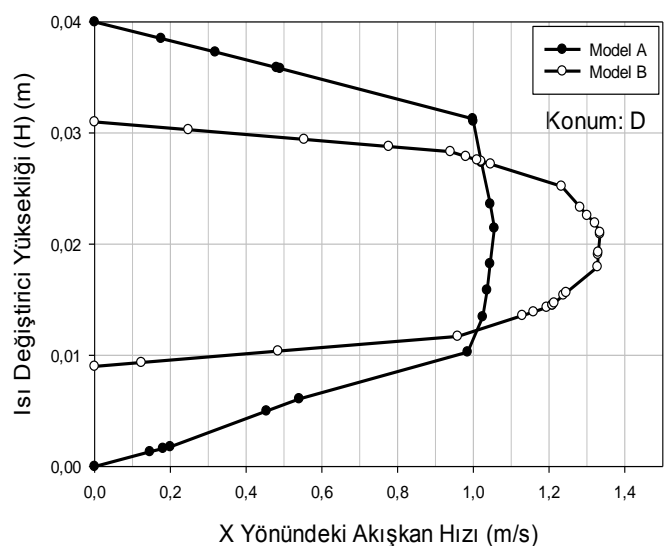

(e)

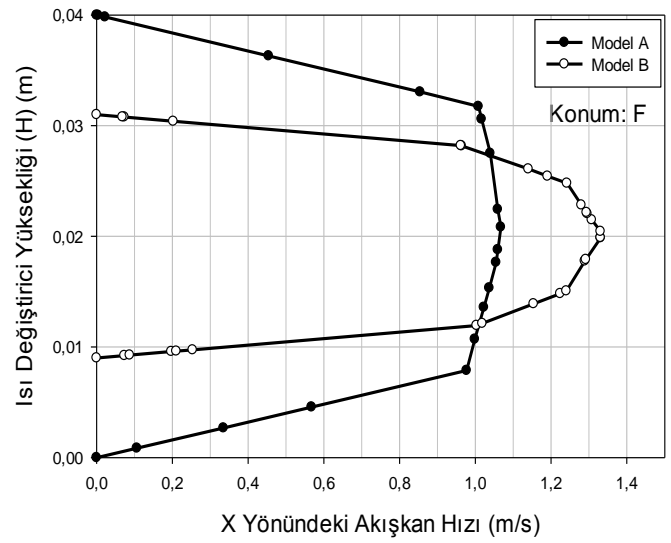

(g)

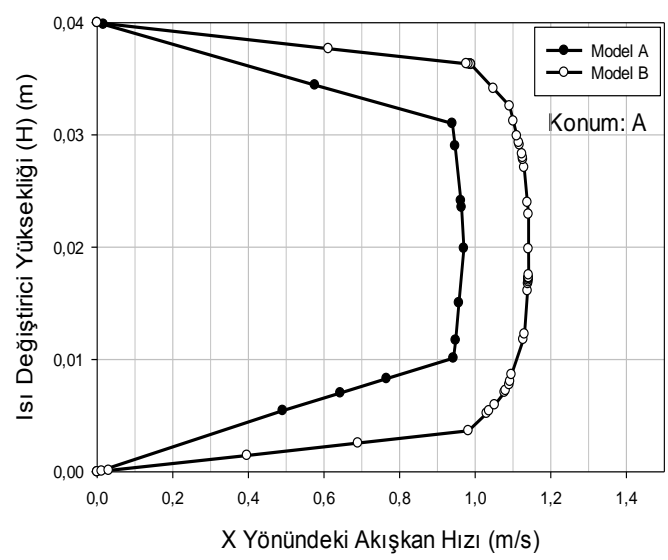

(b)

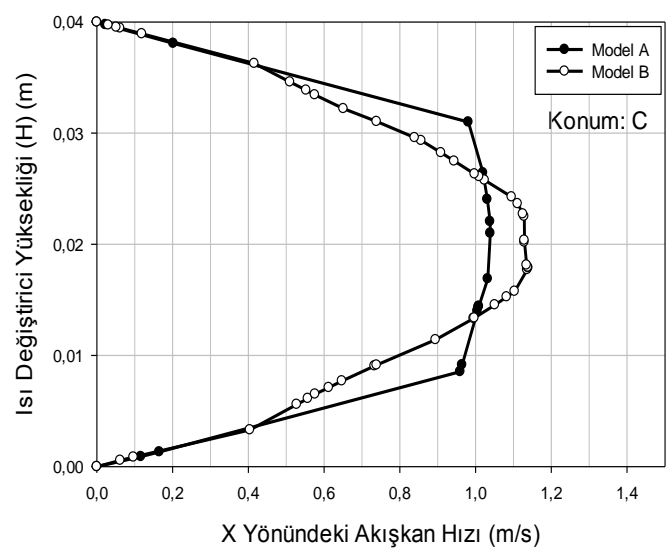

(d)

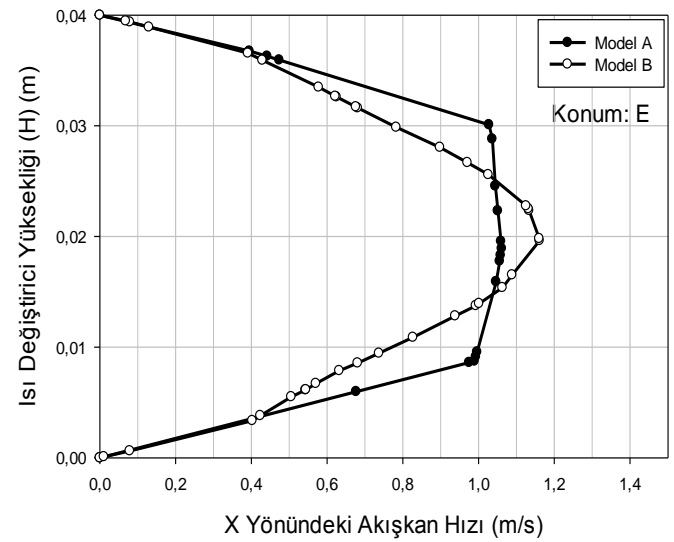

(f)

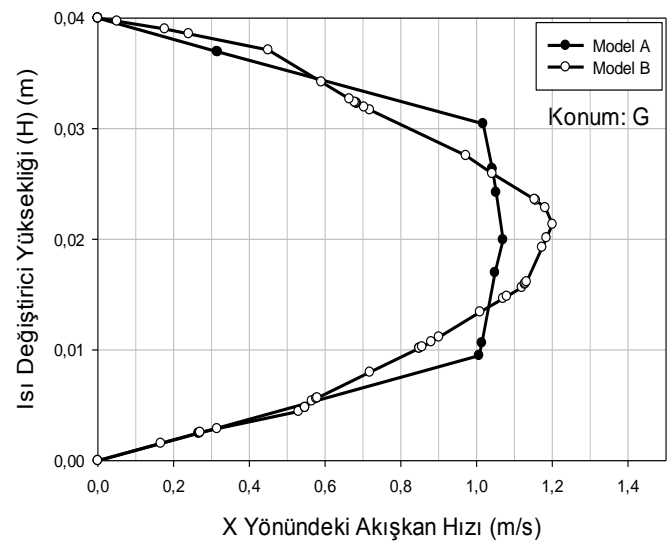

(h)

Şekil 9. X yönündeki akışkan hızları (a) Konum 0, (b) Konum A, (c) Konum B, (d) Konum C, (e) Konum D, (f) Konum E, (g) Konum F, (h) Konum G 


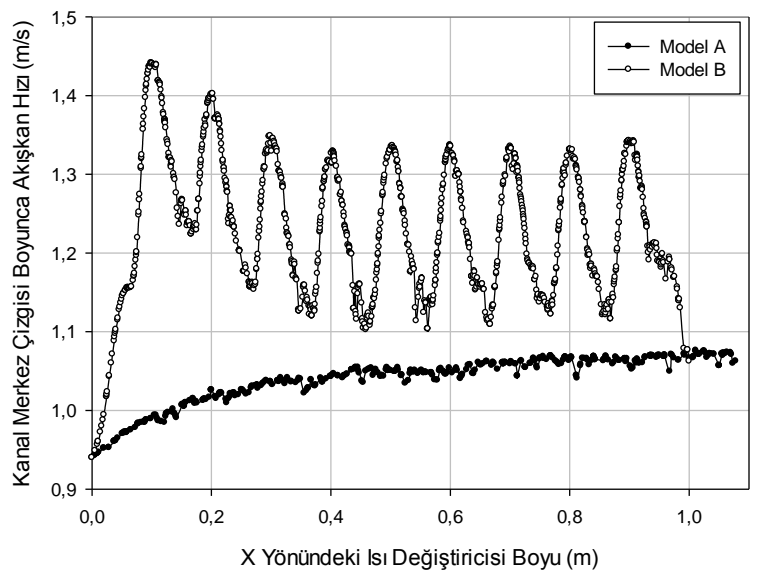

Şekil 10. Isı değiștiricilerin merkezinde bir çizgi boyunca hız profili

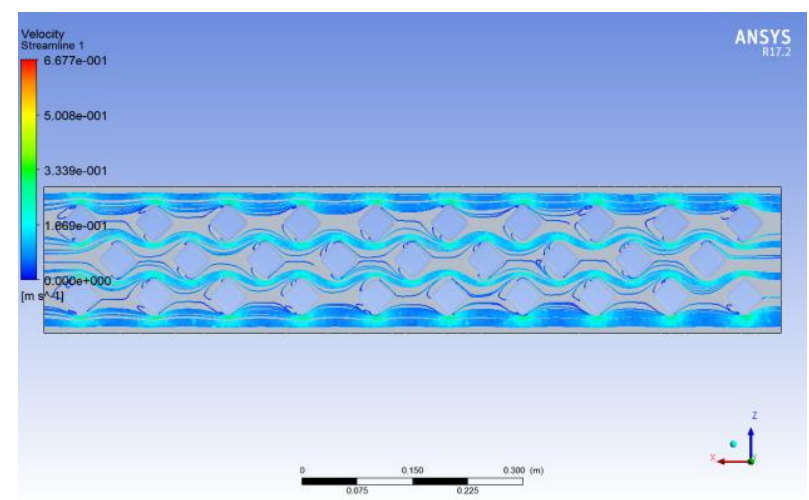

Şekil 11. Model B’nin üst yüzeyinin $1 \mathrm{~mm}$ altındaki akım çizgileri

Hava, burun bölgesinde burun yüzeyini takip ederek desen gövdesine kadar ilerler. Desen gövdesine gelindiğinde enerjinin korunumu denklemine göre desenin kuyruk bölgesine hemen geçildiğinde akış iplikçikleri düzeninde farklılıklar meydana gelmektedir. Hava burun bölgesinde desen yüzeyini takip ederken kinetik enerji düşüşüne uğrayarak basınç enerjisinin artışa geçtiği nokta olan ayrılma noktasına gelir. $\mathrm{Bu}$ noktada akış iplikçikleri birbirinden ayrılmaya başlar. Bu doğrultuda Şekil 11'deki akış iplikçikleri bu bilgiler ile uyumlu olduğu görülmektedir. Ayrıca diğer kütlesel debiler için de diyagonal desenler üzerindeki hız ve basınç enerji değişimleri incelendiğinde; $\dot{\mathrm{m}}=0.004 \mathrm{~kg} / \mathrm{sn}$ 'deki ile aynı olup, desenlerin etkisiyle enerjinin ani olarak değiştiği görülmektedir.

\section{Sonuç}

$\mathrm{Bu}$ çalışmada, dikdörtgenler prizması şeklinde iki ısı değiștirici Ansys Fluent R17.2 programı ile modellenip simüle edilmiștir. Birinci ısı değiștiricide (Model A) bütün yüzeyler düz (desensiz), ikincide ise (Model B) sadece alt ve üst yüzeyleri diyagonal desenli tasarlanmıştır. Isı değiştiricinin yüzeyine eklenen diyagonal desenin akışkanın çıkış sıcaklığına, ısı transfer miktarına, akış hızına, akış alanına ve basınç değişimine etkisi değerlendirilmiştir. Her iki ISı değiştirici için altı farklı $(0.004,0.006,0.008$,
$0.010,0.012,0.014 \mathrm{~kg} / \mathrm{s}$ ) kütlesel debi için nümerik çözümler yapılmıștır.

Isı değiştiricilerden geçen havanın çıkış sıcaklıkları kıyaslandığında; Model B'deki havanın çıkış sıcaklıkları incelenen bütün debiler için Model A'dakinden düşük çıkmıştır. Isı değiştiriciler ıSı transferi açısından incelendiğinde; Model B'deki çeperlerden konveksiyon ve radyasyon yoluyla gerçekleşen isı transferinin Model A'ya göre daha yüksek çıktığı görülmüştür. Sıcaklık ve ısı transferi açısından oluşan bu farklılığın sebebini incelemek için hız profilleri ve ısı değiştiricinin üst yüzeyinden 1 mm altında akım çizgileri oluşturulmuştur. $\mathrm{Bu}$ profiller ve akım çizgilerinden, diyagonal desenlerin akışkanın yüzeylere yakın yerlerdeki hız alanını etkilediği görülmüştür. Hız alanının etkilenmesiyle sınır tabakanın gelişmesi engellenmiş, dolayısıyla isı transferinin arttığı anlaşılmıştır. Sonuç olarak, ISı değiștiricilerine eklenen diyagonal yüzey deseni, Isı transferini artırması durumundan avantaj sağlarken basınç düşüşü açısından dezavantajlı olduğu görülmüştür. Çalışma ile yeni tasarlanacak isı değiștiricilerinde yüzeylere eklenecek desenlerin ısı transferi açısından faydalı olacağı kanaatine varılmış, deneysel yöntemlerde harcanan hammadde ve zamanın kaybolmasını önleyen nümerik çalışmalara katkı sağlanmıştır.

\section{Kaynakça}

[1] Pethkol, S., Eiamsa-ard, S., Kwankaomeng, S., Promvonge, P., 2010. Turbulent Heat Transfer Enhancement in a Heat Exchanger Using Helically Corrugated Tube. Internal Communications in Heat and Mass Transfer, 38, 340-347.

[2] Wang, Y., He, Y., Lei, Y., Zhang, J., 2010. Heat Transfer and Hydrodynamics Analysis of a Novel Dimpled Tube. Experimental Thermal and Fluid Science, 34, 1273-1281.

[3] Garcia, A., Solano, J.P., Vicente, P.G., Viedma, A., 2011. The Infuence of Arifical Rougness on Heat Transfer Enhancement: Corrugated Tubes, Dimpled Tubes and Wire Coils. Applied Thermal Engineering, 35, 196-201.

[4] Carija, Z., Frankovic, B., Perc ic, M., Cavrak, M., 2014. Heat Transfer Analysis of Fin-and-Tube Heat Exchangers With Flat and Louvered Fin Geometries. Internal Journal of Refrigeration, 45, 160-167.

[5] Dizaji, H.S., Jafarmadar, S., Mobadersani, F., 2015. Experimental Studies on Heat Transfer and Pressure Drop Characteristics for New Arrangements of Corrugated Tubes in a Double Pipe Heat Exchanger. Internal Journal of Thermal Science, 96, 211-220.

[6] Yogesh, S.S., Selvaraj, A.S., Ravi, D.K., Rajagoal, T.K.R., 2018. Heat transfer and pressure drop 
characteristics of inclined elliptical fin tube heat exchanger of varying ellipticity ratio using CFD code. International Journal of Heat and Mass Transfer, 119, 26-39.

[7] Zheng, n., Liu, P., Wang, X., Shan, F., Liu, Z., Liu, W., 2017. Numerical simulation and optimization of the heat trenasfer enhancement in a heat exchanger tube fitted with vortex rod inserts. Applied Thermal Engineering, 123, 471484.

[8] Samadifer, M., Toghraie, D., 2018. Numerical simulation of heat transfer enhancement in a plate-fin heat exchanger using a new type of vortex generators. Applied Thermal Engineering, 133, 671-681.

[9] https://www.ansys.com/products/fluids/ansysfluent (Erişim Tarihi: 24.04.2018)
[10] Engin T. ed. 2008. Akışkanlar Mekaniği Temelleri ve Uygulamaları. İzmir Güven Kitabevi, İzmir, 938s.

[11] Bird, R.B., Stewart, W.E., Lightfoot, N. E. Transport Phenomena. Hamilton Printing, United States, 917s.

[12] Derbentli, T. ed. 2006. Isı ve Kütle Geçişinin Temelleri. Literatür Yayınları, İstanbul, 960s.

[13] ANSYS Fluent R17.2 User's Guide, 2017.

[14] Lindeburg, M.R. 2013. Mechanical Engineering Reference Manual for the PE Exam. Professional Publications, Inc, Belmont, California, 1488s. https://books.goole.com.tr (Erişim Tarihi: 01.05.2018)

[15] Mohammedsalih, R. M., 2017. İç İçe Eksenli Boru Türü Isı Değiștiricilerinin Nümerik Araştırılması. Süleyman Demirel Üniversitesi, Fen Bilimleri Enstitüsü, Yüksek Lisans Tezi, 92s, Isparta. 